\title{
Implementation of Fair-exchange and Anonymous Online E-cash Protocol for E-commerce
}

\author{
Harshita \\ Asst. Professor, ITM University, Gwalior, India \\ E-mail: 2014harshita@gmail.com \\ Sarvesh Tanwar \\ Asst. Professor, Mody University of science and technology, Lakshmangarh, India \\ E-mail: s.tanwar1521@gmail.com
}

\begin{abstract}
In the world of internet, e-commerce is one of the most prominent sectors where user wants to shop and pay online for online products. E-cash is one of these payment methods. In e-cash, every time a unique string is generated for user so that user uses that string to pay for any online product. At the time of online purchasing a trust should be maintain between customers and merchant such that the product price which is going to pay by customer is fair or not, the merchant is indeed genuine to deliver the product after getting online payment or not. Trust issues are resolved by using fair exchange concept at the time of online purchasing. Anonymity is also a major concern; it means that true identity of users must be hidden from merchant. By keeping these issues in mind we proposed a protocol which ensures users anonymity by using e-cash payment method and fair exchange by using off-line TTP which invokes by customer when any dispute occur from merchant side. In this paper, we implement our proposed protocol and also analyze its performance and compare it with other protocol.
\end{abstract}

Index Terms-E-cash, Trust, Anonymity, Off-line TTP, Blind Signature.

\section{INTRODUCTION}

With the rapid growth of technology people are able to sell and purchase online products at a click of mouse. This new era of online purchasing is possible because of many electronic commerce transaction protocol which allows user to transact online even by not knowing to each other [6].

There are many types of e-payment methods to do online shopping like credit card, debits card etc. But the main problem with these methods is that sometimes transacting parties' customer and merchant are not known to each other which lead to lack of security and trust. The main trust issue from customer side is that its own identity is not steal by someone on network like credit cards contains the customer information like customer pin number, card - number etc. which are unchangeable for lifetime so that, if any intruder trace information of customer he can be able to use it again or in cryptography language we can say message can be replayed. Sometimes it can be possible that fake merchant steals customer information and make fake payment. Merchant also has some trust issues like after giving product customer will pay merchant or not.

By keeping all these issue in our mind we proposed an anonymous and fair exchange protocol by using e-cash as payment method. We used e-cash as a payment method because each time a new string used by customer as an ecash for unique transaction so that intruder cannot be able to use same e-cash again and it do not contains the true identity of customer.

The main aim of our research is to propose a protocol which provides fair exchange of product/payment to both transacting parties' and identity of customer should be anonymous to merchant or any other outsider on network.

\section{RELATED WORKS}

In this section we are going to briefly describe some previous works and also compare our work with them. David Chaum in 1982 proposed blind signature to hide true identity of customer which is known as anonymity [6]. To achieve fair exchange in e-commerce many protocols uses off-line as well as on-line TTP protocol [13] [15].

E-cash can be implemented as offline or online. In offline, e-cash is kept by consumer in a device such as smart card or any other type of token [4].We have developed an online e-cash protocol using offline TTP model in which e-cash is kept by bank in his database.

A major difference between offline and online e-cash protocol is that in online protocol bank has to be present all time while doing transaction but in offline bank is not present at all time of transaction. In the past, many e-cash and fair exchange protocol are implemented by researchers. The author [8] proposed an approach which built the trust factor between customer and merchant by 
using offline TTP model which invokes when any disputes takes place. But their protocol contains some attacks which overcome by [11]. There are many cryptographic algorithms applied to develop e-cash protocol which describes by [6]. For keeping e-cash one need to have some software like e-wallet installed in their pc, smart disk or mobile.

The author [5], implements the software to keep database of electronic cash between the user and the bank. By storing e-cash on hard disk have many dis-advantages like, crashing of hard disk, stealing of hard disk and any technical fault. The author [10], proposed an online ecash protocol in which bank keeps e-cash in its database.

For achieving fa ir exchange many researchers' [9] [22] [3], used on-line TTP model which ensures fair exchange but leads to bottleneck problem. In [9], author proposed a protocol in which TTP cannot read any information but only verify the intended parties i.e. customer and merchant.

To reduce bottleneck protocol author [22], proposed protocol in which bank acts as TTP but their protocol do not achieve fair exchange. To improve the performance [14], proposed a new protocol in which bank gives license to customer but it also been analyzed that their protocol breaches customer anonymity.

Many off-line e-cash schemes developed by [15] [18] [19], but it needs lots of mathematical calculation so find out the double spender of e-cash.

In this paper, we proposed an on-line e-cash protocol which does not require lots of mathematical computation for finding double spending also the e-cash stored in bank's database in secure form. To maintain the trust between customer and merchant we used compatible keys concept. We have also analyzed our protocol with other protocols. The rest of the paper is organized as follows in section 2, we described basic concept used to develop protocol. Section 3 describes steps of protocol and result and analysis describes in section 4. We have also developed dispute protocol in which customer invokes TTP while any dispute occurs from merchant. Finally section 5, describes conclusion of paper.

\section{BASIC CONCEPTS}

In this section, we are going to describe two main properties of proposed protocol.

\section{A. Blind Signature}

Blind signature is a form of digital signature in which message is not seen by signer while signing. Blind signatures used to provide unlink ability, which do not allows signer to link blinded message with actual message but signer can be able to verify it and keeps sender privacy. It can be implemented by using concept of RSA. In our work we applied blind signature for signing actual value of e-cash from bank. The steps of making blind signature are given as follows: -
1) Choose a random factor $\mathrm{r}$ in $Z_{n}^{*}$ such that ged (r, n) $=1$

2) Blind e-cash using above random factor $=r^{e b}(\mathrm{e}-$ cash) $\bmod n$

Now, bank will sign above blinded e-cash using his own private key and sends signed blinded e-cash to customer. After receiving signed blinded e-cash, customer un-blinds received e-cash. The steps of removing blinding factor for e-cash is describes in below steps

1) Signed e-cash $\left.=r^{e b}(\mathrm{e}-\mathrm{cash})^{\mathrm{db}} \bmod \mathrm{n}\right)$

2) $\left(r^{e b * d b} \operatorname{modn}\right)\left((e-c a s h)^{d b} \bmod n\right), \mathrm{e}^{*} \mathrm{~d} \bmod$ $\mathrm{n}=1$ (RSA property)

3) $(r)\left(\frac{(e-c a s h)^{d b} \text { modn }}{r}\right)$

4) Un-blind e-cash $=(e-c a s h)^{d b} \operatorname{modn}$

Here, $\mathrm{db}$ is bank's private key and eb is bank's public key and $\mathrm{n}$ is modulus of public and private key of bank. $Z_{n}^{*}$ Is subgroup of $Z_{n}$ which contains elements which have unique multiplicative inverse.

\section{B. Compatible Keys}

We used compatible keys to make trust between customer and merchant which was proposed by ray et.al [8]. The steps of making compatible keys are given as below: -

i) Let $m$ be the product which is encrypted with the public key $(\mathrm{e}, \mathrm{n} 1)$ generated by TTP whereas TTP keeps $(\mathrm{d} 1, \mathrm{n} 1)$ with itself.

ii) Now, merchant also have (e, n1) and make compatible keys (e, n2) and (d2, n2) with itself. In compatible keys e should be the same where $(n, d)$ key pairs are different.

iii) For proof of theorem let us take a message $\mathrm{m}$ encrypted with $(\mathrm{m}, \mathrm{e}, \mathrm{n} 1)$ and same message encrypted with (m, e, n1*n2).

iv) $\quad(\mathrm{m}, \mathrm{e}, \mathrm{n} 1)=\left(\mathrm{m}, \mathrm{e}, \mathrm{n} 1{ }^{*} \mathrm{n} 2\right)$

v) $\quad m^{e} \bmod n 1=m^{e} \bmod n 1 * n 2$

vi) $m^{e} \bmod n 1=m^{e} \bmod n 1(\bmod n 1)$

vii) $m^{e} \bmod n 1=m^{e} \bmod n 1$

viii) $m=m$, LHS $=$ RHS hence proved.

\section{PROPOSED PROTOCOL}

The protocol consists of five main phases; Initial setup, registration phase, Issue of e-cash phase, payment and deposit phase. We have also developed extended e-cash dispute algorithm. The block diagram of proposed protocol is given in fig. 1. Bank has three databases: client info, new coin and spend coin in which fresh coin database contains not used coin information whereas spend coin database contains used coin information. 


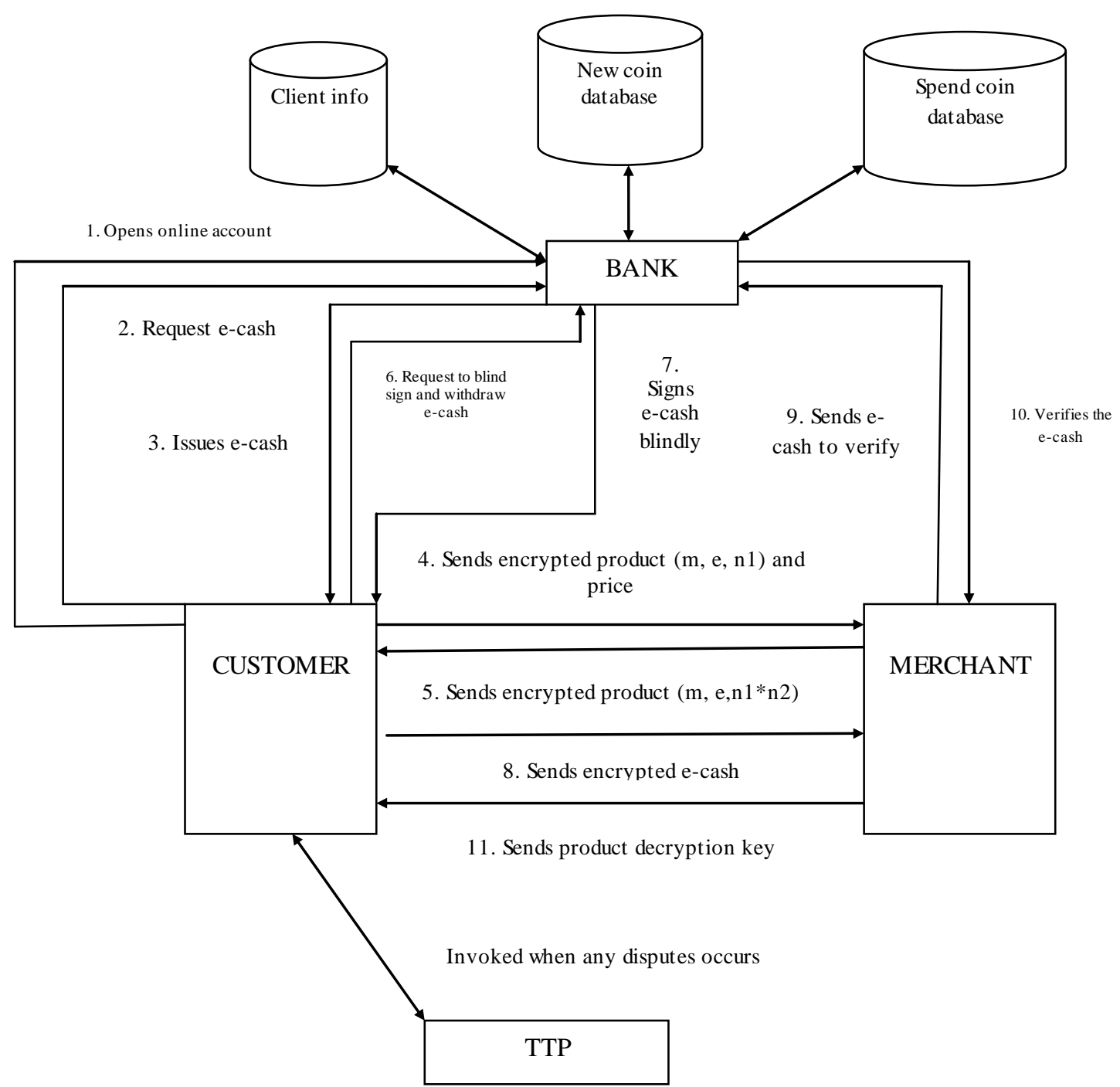

Fig.1. Block Diagram of Protocol

The working of each phase is describes in below steps:

\section{1). Initial Setup}

First of all bank, merchant and TTP gets their public key certificate from the CA (for this we assumed that they already have applied to CA) and publish their public key online and keeps their private key separately with them. Merchant also gets the product certificate from TTP. For this he registers the product with TTP whereas TTP calculates different product key for each product i.e. public and private key pair using RSA algorithm and encrypt the product with public key which is denoted by (e, n1) and publish on website. Now the product which is seen by customer is in encrypted form (m, e, n1) along with its cost and name. Merchant also calculates the compatible public private key pair for that product which is represented as $(e, n 2)$ and $(\mathrm{d} 2, \mathrm{n} 2)$ and keeps keys with him. Table 1 describes various notations used in our protocol.

\section{2). Registration Phase}

In registration phase, for signing message we used asymmetric key because customer do not have any public and private key pair. For asymmetric key encryption we used AES-128.

i)

$$
\begin{gathered}
\text { Customer } \longrightarrow \text { Bank } \\
E_{\text {bank }_{e}}\left(\text { user }_{\text {id }}+\text { time }_{\text {customer }}+\text { seceret_key }_{+}+\right. \\
\left.E K_{\text {password_cust }}(H(m s g))\right)
\end{gathered}
$$

In eq. 1, customer first of all opens online bank account by entering user-id and password which was given earlier by bank and chooses security which later acts as asymmetric key.

\section{3). Issuing E-cash}

We have used online system for storing e-cash rather than using e-wallet concept. For is suing e-cash first of all customer login into the online e-cash bank and apply for e-cash than bank gives the e-cash by generating some random serial co in like " 191043011281012345 ". In this representation of coin 191 is bank number, 0430 coin creation date, 112810 ("mmss") is coin creation time and 
12345 is random serial number which issued to customer and hash of e-cash with its expiry date is stored in new coin database of bank.

Table 1. Notations used in Protocol

\begin{tabular}{|c|c|}
\hline Symbol & Description \\
\hline EK & Encrypted using asymmetric key \\
\hline $\mathrm{E}(\mathrm{msg})$ & E stands for encryption using public key \\
\hline$E_{\text {bank_e }}, E_{\text {merchant_e }}, E_{t t p_{-} e}$ & $\begin{array}{l}\text { bank public key, merchant public key and TTP public } \\
\text { key }\end{array}$ \\
\hline user $_{i d}$ & User identification basically cust omer id \\
\hline$E_{\text {password_cust }}$ & Password of cust omer \\
\hline $\mathrm{H}(\mathrm{msg})$ & Hash of message using hash algorithm \\
\hline time $_{\text {customer }}$, time $_{\text {bank }}$, time $_{\text {merchant }}$, time $_{\text {ttp }}$ & Time of cust omer, merchant, TTP and bank \\
\hline$E_{\text {merchant_d }}, E_{\text {bank_d }_{-}}, E_{t t p_{-} d}$ & Merchant, bank and TTP private key \\
\hline$(\mathrm{m}, \mathrm{e}, \mathrm{n} 1 * \mathrm{n} 2)$ & Message $m$ is encrypted with compatible public key \\
\hline$E_{\text {cust_temp_d }}$ & Customer temporary privatekey \\
\hline$E_{\text {temp_e }}, E_{\text {temp_n }}$ & Cust omer temporary public key for each transaction \\
\hline
\end{tabular}

\section{4). Withdrawal Phase}

In this phase, before sending withdrawal request to bank customer first creates trust between merchant and himself by sending encrypted product and cost to merchant and takes merchant signs on encrypted product. In eq. 2, customer first of all creates temporary private public key pair (note that this is temporary key pair for each transaction) to hides its true identity because temporary key pair does not contains any information of customer and sends to merchant along with cost and encrypted product.

i)

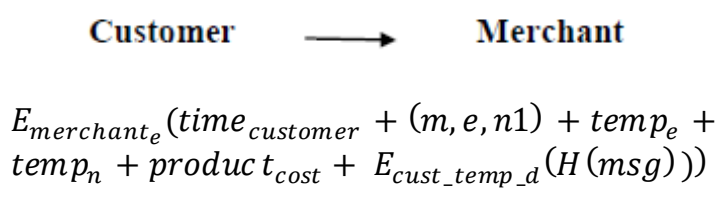

Eq. 2 contains:

1.) (m, e, n1) encrypted product details

2.) Timestamp for avoiding replay attack.

3.) $E_{\text {cust_temp_d }}(H(m s g))$ Signed message using customer temporary private key pair.

ii)

\section{Merchant $\longrightarrow$ Customer}

Merchant decrypts eq. 2 by its private key and checks whether all details regarding product is correct or not. Merchant also checks digital signature and timestamp of message is correct. If all the details are correct than merchant sends product encrypted with compatible key along with its signature on it to customer.

$$
\begin{gathered}
{\text { cust } \text { temp }_{e}}((m, e, n 1 * n 2)+ \\
\text { time }_{\text {customer }}+\text { time }_{\text {merchant }}+\operatorname{sign}_{\text {merchant }}(m, e, n 1 * \\
\left.n 2)+E_{\text {merchant }_{d}}(H(m s g))\right)
\end{gathered}
$$

iii)

\section{Customer $\longrightarrow$ Bank}

Now, after receiving eq. 3 customers checks the sign of merchant on product and also checks price of product with sending price. After getting trust on merchant customer sends e-cash withdrawal request to bank and sends hash value of actual e-cash with blinded e-cash because to maintain customer anonymity from bank customer sends blinded e-cash. Blinded e-cash contains (ecash xor amount) because later bank will able to verify both e-cash and amount.

$$
\begin{gathered}
E_{{\text {ban } k_{e}}}\left(\text { user }_{i d}+\text { Hash }(\text { ecash })+\text { blinded ecas } h+\right. \\
\text { amount } \left.+ \text { EK } K_{\text {security_key }}(H(m s g))\right)
\end{gathered}
$$

iv)

\section{Bank $\longrightarrow \quad$ Customer}

After receiv ing eq. 4, bank first checks whether hash of e-cash present in new coin database or not. If it present in new coin database than bank comes let to know that customer is genuine and sends signed e-cash to customer.

$$
\begin{gathered}
E K_{\text {securit }} y_{\text {key }}\left(\text { user }_{\text {id }}+\text { signed }- \text { ecash }+\right. \\
\left.E_{\text {bank_d }}(H(m s g))\right)
\end{gathered}
$$

After receiving eq. 5, customers first decrypts message by using its own symmetric security key then checks bank signature on message and gets the signed e-cash by removing its blinding factor.

Now representation of e-cash coin will be ((ecash xor amount $)^{d b} \operatorname{modn}$, e-cash, amount) this will be send to the merchant.

\section{5). Payment and Deposit Phase}

In this phase, customer sends e-cash, encrypted product and sign of merchant on encrypted product to merchant. 
Here, e-cash is again encrypted with bank's public key so that merchant is not able to see it. The message will be in form of eq. 6 .

i.)

$$
\begin{gathered}
\text { Customer } \longrightarrow \text { Merchant } \\
E_{\text {merchant }_{e}}\left((m, e, n 1 * n 2)+\text { time }_{\text {customer }}+\right. \\
\operatorname{sign}_{\text {merchant }}(m, e, n 1 * n 2)+\text { encrypted ecash }+ \\
\left.E_{\text {cust_temp_d }}(H(m s g))\right)
\end{gathered}
$$

After receiving information from customer, merchant sends encrypted e-cash, product cost, his own account number and a unique transaction-id to bank.

ii)

$$
\begin{gathered}
\text { Merchant } \longrightarrow \text { Bank } \\
E_{\text {bank }_{e}}\left(\text { encrypted ecash }+ \text { cost }_{\text {of } \text { product }}+\right. \\
\text { time }_{\text {merchant }}+\text { accoun }_{n o}+{\text { transcatio } n_{i d}}+ \\
\left.E_{\text {merchant_d }}(H(m s g))\right)
\end{gathered}
$$

After receiving message from merchant bank, first of all decrypts encrypted e-cash with his own private key than checks his signature on (e-cash xor amount). If everything is alright than also verifies e-cash amount with cost of product and checks the specified e-cash number has already been spent before or not. After checking double spender, bank credits genuine merchant account with appropriate amount.

iii)

$$
\begin{gathered}
\text { Merchant } \longrightarrow \text { Customer } \\
E_{\text {cus }_{\text {temp }_{e}}}\left(\text { product }_{\text {decryption }}\right. \text { key } \\
\text { time } \left._{\text {merchant }}+\text { tramsaction_id }_{\text {customer }}+E_{\text {merchant_d }}(H(m s g))\right)
\end{gathered}
$$

After receiving transaction successful message from bank genuine merchant will sends product decryption key to his customer along with unique transaction id in form of eq. 8.

\section{6). Dispute Algorithm}

For achieving fair exchange we used off-line TTP model in which merchant has to registers their products first with TTP before publishing on web. As we have seen that before start of transaction customer obtained merchant signature on encrypted product this will leads to maintain trust between customer and merchant but in worst cases it can be possible that merchant cheat's customer. There are two ways in which merchant can cheats customer:-

Case 1: Merchant do not sends product key after receiving payment.

Case 2: Merchant sends incorrect product key after receiving payment.
Here we implemented the case 2 for this protocol. But there will be less chances of dispute occurrence because at time of trust building customer first gets merchant signature on encrypted product so the genuine merchant never do cheating because customer can sends the signed message to TTP for taking some action against merchant. The steps of dispute algorithm are given as below:

i)

\section{Customer $\longrightarrow$ TTP}

In this step, customer sends all the information regarding merchant, e-cash and product to TTP after getting wrong product from merchant.

$$
\begin{gathered}
E_{\text {ttp }}\left(\text { encrypted ecash }+ \text { time }_{\text {customer }}+\right. \\
\text { merhcant } \\
\text { id } \\
+(m, e, n 1 * n 2)+ \\
\text { sign }_{\text {merchant }}(m, e, n 1 * n 2)+\text { temp } p_{e}+\text { temp } p_{n}+ \\
\text { transaction_id } \left.+E_{\text {cust_temp_d }}(H(m s g))\right)
\end{gathered}
$$

ii)

$$
\text { TTP } \longrightarrow \quad \text { Bank }
$$

Now, after receiv ing eq. 9 from customer bank sends ecash to bank for knowing that whether this e-cash is already been spent or not because it may be possible that fake customer built a random string and sends to TTP and claims that merchant didn't send right product.

$$
\begin{aligned}
& E_{{\text {ban } k_{e}}} \text { (encrypted ecash }+ \text { time }_{t t p}+ \\
& \left.E_{t t p_{d}}(H(m s g))\right)
\end{aligned}
$$

iii)

\section{TTP $\longrightarrow \quad$ Merchant}

After getting a good acknowledgement from bank that customer is fair this e-cash is already spent, TTP sends following information to merchant and starts a timer that merchant have to respond on that time otherwise TTP will take an appropriate action against it.

$$
\begin{gathered}
E_{\text {merchant }_{e}}\left((m, e, n 1 * n 2)+\text { time }_{t t p}+\right. \\
\operatorname{sign}_{\text {merchant }}(m, e, n 1 * n 2)+\text { trnasaction }_{i d}+ \\
\left.E_{t t p_{\_} d}(H(m s g))\right)
\end{gathered}
$$

iv)

\section{Merchant $\longrightarrow$ TTP}

If merchant responds in time then the TTP receives eq. 12 otherwise TTP receives " 0 " message.

Merchant to TTP, timer expires message="0";

Or 


$$
\begin{gathered}
E_{t t p_{e}}\left(\text { product }_{\text {decryption }} \text { key }+ \text { time }_{t t p}+\right. \\
\text { time } \left.e_{\text {merchant }}+E_{\text {merchant_d }}(H(m s g))\right)
\end{gathered}
$$

v)

\section{TTP $\longrightarrow \quad$ Customer}

In last step of this algorithm if merchant did not sends any product decryption key to TTP, TTP will sends product key from $\mathrm{h}$ is own database to customer and takes some appropriate action against merchant.

$$
\begin{gathered}
E_{\text {cust }_{\text {temp }}}\left(\text { product }_{\text {decryption }} \text { key }+ \text { time }_{\text {customer }}+\right. \\
\text { time } \left._{t t p}+E_{\text {ttp_d }}(H(m s g))\right)
\end{gathered}
$$

\section{EXPERIMENT RESULT AND ANALYSIS}

We have developed our protocol in java using socket programming. We have also performed an experiment over four systems which acts as customer, bank, merchant and TTP. Later, in this section we analyzed performance of our protocol with on-line TTP protocol. First of all customer need to open his online account in respective bank and is sues e-cash as shown in fig. 2 .

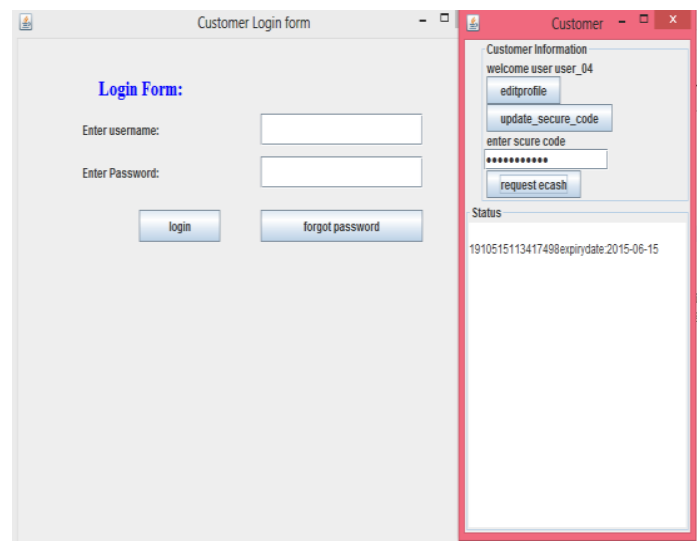

Fig.2. Issue of E-cash

Merchant_store[ Java Application]C:Program Filesłjavalbinljavaw. exe

Receiver activated and has been connected to server

Merchant IP address $/ 10.20 .131 .12$. at port 7743

Connected to merchant

Customer making anonymous identity and sending encrypted message to merchant Msg: 7024377780416516526434346726719264736746354635465346635613

Time of sending message is: $2015-05-15+10: 58: 51$

Customer gets encrypted product from merchant using ( $\left.\mathrm{m}, \mathrm{e}, \mathrm{n} 1 *_{\mathrm{n}} 2\right)$

\section{1}

Customer verifying product sign;

\section{$06 \mathrm{e} 5 \mathrm{ab} 99 \mathrm{c} 975 \mathrm{~d} 8 \mathrm{cb} 7 \mathrm{~b} 374 \mathrm{~b} 7 \mathrm{fb} 8127382 \mathrm{e} 383783$}

Customer sending and receiving time has been verified

Fig.3. Customer Sends and Receives Encrypted Product to and from Merchant
After issuing of e-cash, customer goes to online merchant store and selects a product after selecting product customer sends eq. 2 to merchant in encrypted form and receives eq. 3 shown in fig. 3 .

After receiving a trust factor and signature from merchant on product, customers sends withdrawal request to bank in fig. 4. We have also used OTP (one time password) for customer authentication. Customer blinds the actual value of e-cash and sends hash of e-cash to bank so that bank can be able to check that this e-cash is already been spent before or not.

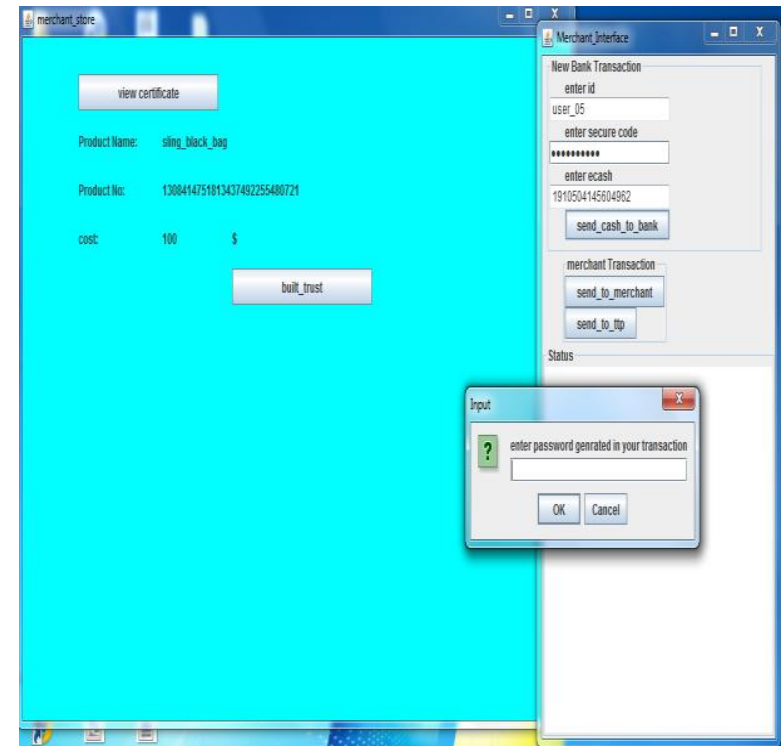

Fig.4. Customer Fills Withdrawal Sends E-Cash Withdrawal Request to Bank

After receiving withdrawal request, bank will sends signed blinded e-cash to customer and debits respective amount from customer account. The bank operation is shown in fig. 5 .

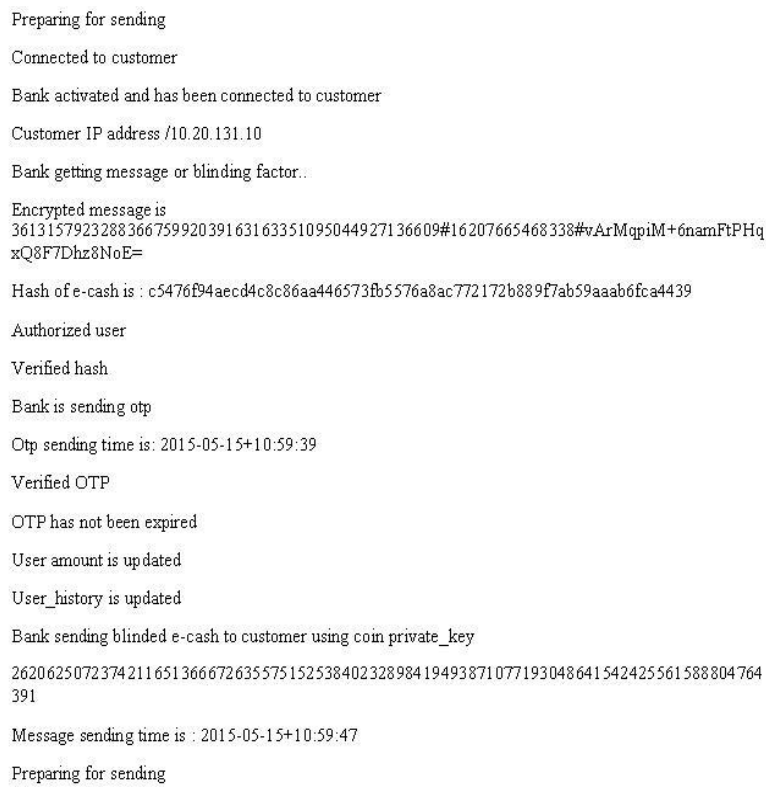

Fig.5. Bank Sends Blinded E-cash to Customer 
After receiving signed blinded e-cash customer removes blind factor ' $r$ ' and again encrypts e-cash with bank's public key and sends eq. 6 to merchant

After receiving signed blinded e-cash customer removes blind factor ' $r$ ' and again encrypts e-cash with bank's public key and sends eq. 6 to merchant.

After receiving e-cash from customer merchant sends them to bank for crediting his own account and later sends correct product key to customer which shown in fig.6. If in any case, customer receives wrong product than customer invokes dispute algorithm in which customer sends all the details regarding merchant and product to TTP than TTP will forwards the details to bank for knowing whether customer is playing fair or not.

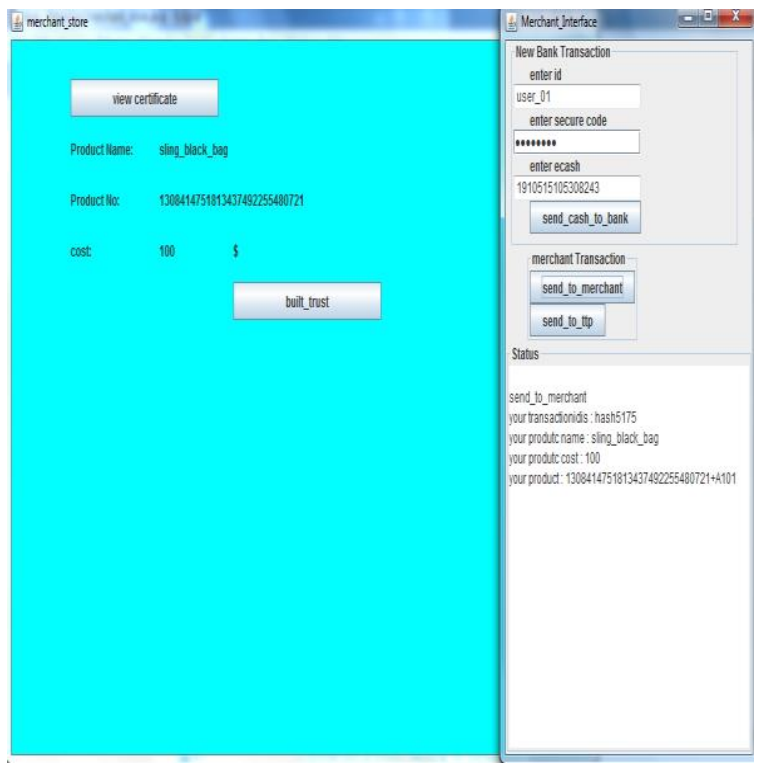

Fig.6. Customer Receives Correct Product from Merchant

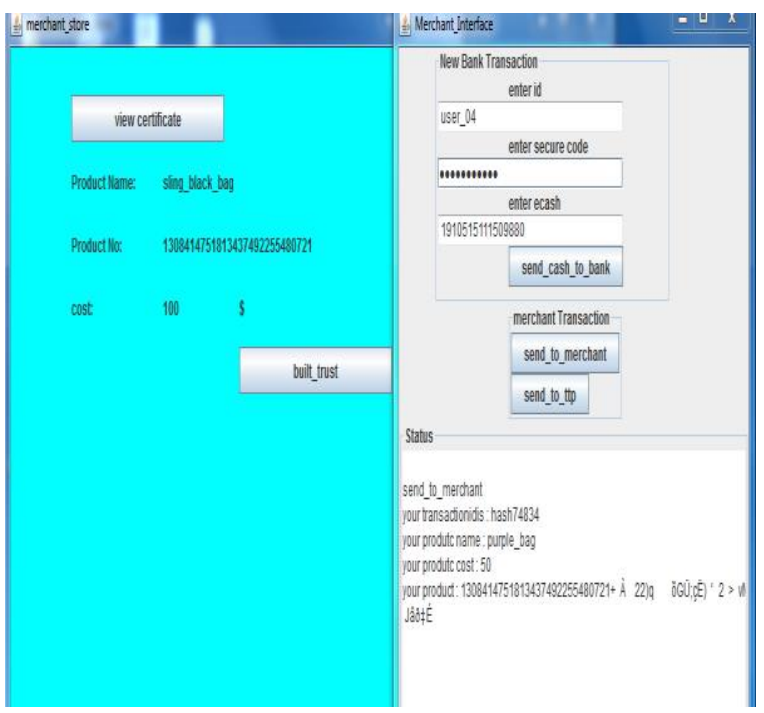

Fig.7. Customer Receives Incorrect Product Details

After getting acknowledgement from bank TTP forwards message to merchant and waits till merchant reply. Fig. 7 shows that customer receives incorrect product which is different from the product which was requested by customer. Fig. 8 shows that TTP starts a timer and merchant didn't response in that time then TTP forwards correct product key from his database to customer.

We have also analyzed our protocol in terms of time by calculating time of each phase shown in fig. 9. The performance of system is good enough even with increase in the number of users. We calculated the time of each phase up to 8 customers which request to buy a product using on-line e-cash protocol. Basically, the time of withdrawal phase is more than two phases i.e. deposit and payment phases, because in withdrawal phase time depends upon time to enter one time password. The time also depends upon how much crypto operations applied on each phase of protocol.

ttp[Java Application] C:Program File'Javaibiniljavaw.exe[ May4,2015]

Preparing for sending

Connected to customer

TTp activated and has been connected to customer

Customer IP address $/ 10.20 .131 .10$ at port 6691

Message from customer

TTP sending E-cash to bank for checking

158347751237491798615872666725658653286154654123243167637632

TTP connected to bank

Waiting to connect

Connected to bank

Client: 1

Message comes from bank: 1

Customer is fair

Merchant IP address $/ 10.20 .131 .12$ at port no 7773

Waiting to connect

Connected to merchant

Sender: waiting for message from merchant

Message is: 0

Terminating merchant not respond times out

TTP sending message to customer

Preparing for sending

Fig.8. Merchant Didn't Response in Given Time and Timeout Error Occurs

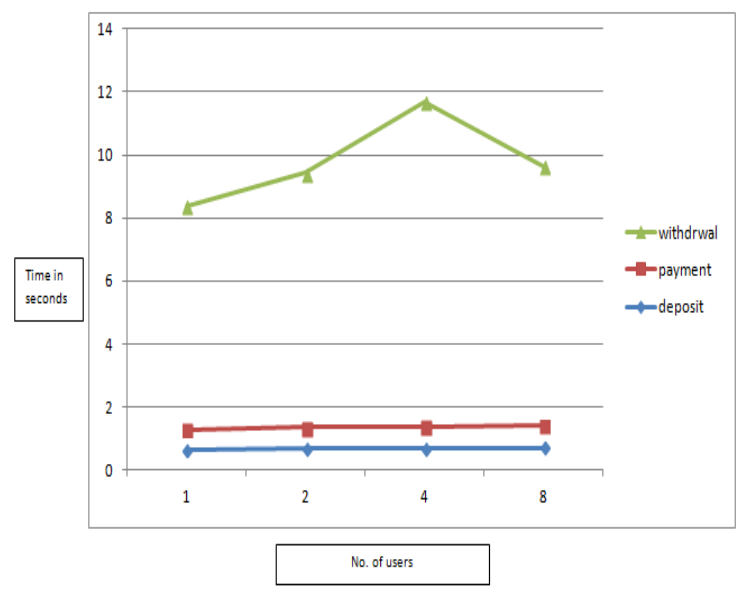

Fig.9. Time Calculation Graph

We calculated difference of our protocol with on line TTP protocol in terms of time taken in payment phase and it shows that our protocol gives better result than online TTP protocol. Fig.10. shows the timing difference 
of payment phase.

We also compared our offline TTP protocol with online TTP e-cash protocol in which there is no direct contact between merchant and customer takes place.

In online TTP protocol there is no use of making compatible keys because customer is not going to make direct communication with merchant. By using online TTP there is guarantee of fair exchange but sometime TTP will becomes a bottleneck problem.

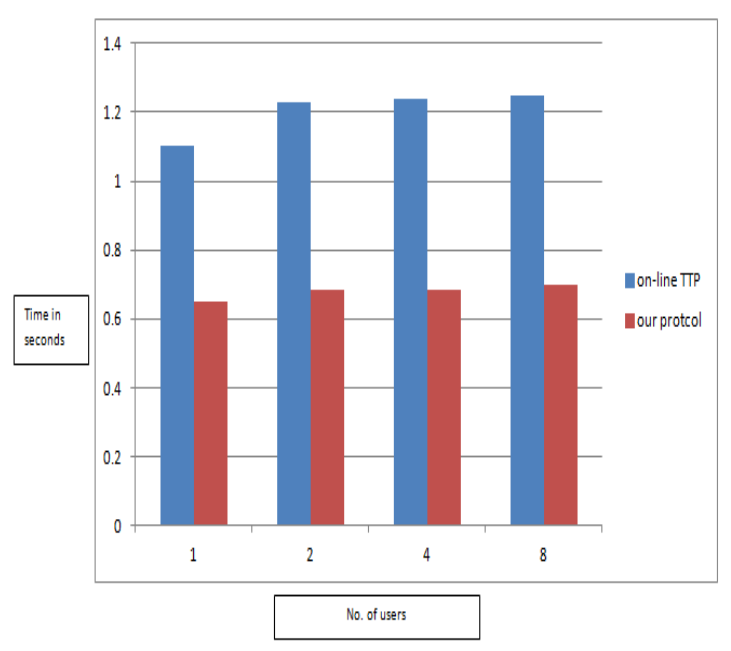

Fig.10. Time Calculation Graph of Payment Phase

Some researchers [11] [23] also proposed online e-cash protocol but their protocol have still some weakness. In table 2, we compare our protocol with some already proposed e-cash protocols.

Table 2. Comparison between Song, Swe and Our Protocol

\begin{tabular}{|c|c|c|}
\hline Song & Swe & Proposed protocol \\
\hline $\begin{array}{l}\text { Customer uses } \\
\text { asymmetric } \\
\text { cryptography in } \\
\text { withdrawing phase }\end{array}$ & $\begin{array}{l}\text { Customer uses } \\
\text { asymmetric } \\
\text { cryptography in } \\
\text { withdrawing phase }\end{array}$ & $\begin{array}{l}\text { Author uses hybrid } \\
\text { cryptography } \\
\text { (symmetric with } \\
\text { asymmetric) in } \\
\text { withdrawing phase }\end{array}$ \\
\hline $\begin{array}{lr}\text { Protocol fail to } \\
\text { provide } \\
\text { exchange }\end{array}$ & $\begin{array}{l}\text { Improvement over } \\
\text { song protocol but } \\
\text { while providing fair } \\
\text { exchange anonymity } \\
\text { of customer } \\
\text { breaches }\end{array}$ & $\begin{array}{l}\text { Provides anonymity } \\
\text { and fair exchange to } \\
\text { customer. }\end{array}$ \\
\hline
\end{tabular}

\section{CONCLUSION}

In this paper, we worked on on-line e-cash protocol which acts as online pay ment method. Basically e-cash is in the form of some strings or bits and should be anonymous in nature. For achieving anonymity we used blind signature. The protocol ensures all the features of cryptography by using public key as well as private key cryptography. For fair exchanging of online products we used offline TTP. The protocol is also sufficient against replay attacks and we used the concept of OTP for achieving authentication of user. Even at login time of customer on bank timestamp also gets attached along with user-id and password so that if any attacker traces the sent message and later sends it to bank than attack can be detected by receiving parties. By using on-line e-cash protocol user can be able to do transaction from any location which makes it more users friendly.

We also performed an experiment on four systems and also calculated the timing difference of each phase and it shows that even with increase in number of user protocol takes less time than on-line TTP protocol.

The protocol can be enhanced by fixing e-cash value to some denomination earlier. The bank and TTP also acts as one server rather than using two different servers.

\section{REFERENCES}

[1] C. Tianhuang and X. Xiaoguang. "Digital signature in the application of e-commerce security." IEEE International conference on E-Health Networking, Digital Ecosystems and Technologies, 2010, pp.366-369.

[2] M. I. Laden. "E-commerce Securitv Issues." IEEE International conference on future Internet and cloud, 2014, pp. 197-201.

[3] M. Alarai and M. Munro. "Enforcing Honesty in Fair Exchange Protocols." Springer Emergent Web Intelligence: Advanced Semantic Technologies, 2010, pp. 451-479.

[4] S. Srivastava and V. Saraswat, "E-Cash Payment Protocols." International Journal on Computer Science and Engineering, vol. 4, 2012, pp. 1603-1607.

[5] G. Sharma. M. Mathur and K. Mathur. "Phvsical Securitv Aspects of E-Cash." IEEE Communication Systems and Network Technologies, 2014, pp.772-775.

[6] Schoenmakers, "Basic Security of the e-cash Payment System". Computer security and Industrial Cryptography: State of the art and evolution, Esta Course Leuven Belgium, 2002, pp.3-6.

[7] D. Raffo, T. Clausen, A. Laouiti and P. Muhlethaler, "Securing the OLSR routing protocol with or without compromised nodes in the network", HAL archivesovertes. 2005. pD. 55.

[8] Ray, I. Ray, and N. Natarajan. "An anony mous and failure resilient fair-exchange e-commerce protocol." Decision Support Systems Science Direct, vol.39, 2005, pp. 267292.

[9] Alaahtani. "A Fair Exchange \& Customer Anonvmitv Protocol Using A Trusted Third Party for Electronic Commerce Transactions \& Payments." International Journal of Network Security \& Its Applications, vol.6, 2014, pp. 59-74.

[10] A. Swe and K.K. Khat. "Design and Formal Analvsis of E-cash System." International iournal of scientific engineering and technology research. Vol.03, 2014, pp.3318-3321.

[11] N. Htun and K. K. Kyaw. "Security Improvement on an Anonvmous Fair Exchange E-commerce Protocol." International conference on advances in engineering and technology, Singap ore, 2014, pp. 217-221.

[12] Swe and K. K. Ky aw, "Formal Analy sis of Secure E-cash Transaction Protocol." IIENG, International conference on advances in engineering and technology, Singapore, 2014, pp. 45-48

[13] Y. Baseri, B. Takhtaei, and J. Mohajeri, "Secure untraceable off-line electronic cash system." Science Direct, vol. 20, 2013, pp.637-646.

[14] Swe and K. K. Kvaw. "Improved E-cash Protocol." International iournal of scientific \& technology research, 2013, pp. 28-30. 
[15] C. Wang, "An improved off-line electronic cash scheme." IEEE Computational and Information Sciences, 2013, pp. 438-441.

[16] D. Sudhakar "e-Cash- Electronic Cash Payment: a System without Use of Paper or Coins", International Journal of Scientific Research, vol.2, 2013, pp.1-3.

[17] P. Sarkar, "Multiple-Use Transferable E-Cash." International iournal of computer applications, vol.77, 2013, pp. 854- 858.

[18] Miers. C. Garman. M. Green. and A. Rubin. "Zerocoin: Anonymous distributed e-cash from bitcoin." IEEE, Security and Privacy (SP), 2013, pp. 397-411.

[19] Z. Eslami and M. Talebi, "A new untraceable off-line electronic cash system." Science Direct, Electronic Commerce Research and Applications, vol.11, 2011, pp. 59-66.

[20] J. Camenisch, A. Lysyanskaya and M. Meyerovich, "Endorsed E-Cash." IEEE Symposium on Security and Privacy. Vol. 7. 2007, 101-115.

[21] Y. Ling. Y. Xiang and X. Wang. "RSA-based secure electronic cash payment system." IEEE Conference on Industrial Engineering and Engineering Management, 2007, pp. 1898-1902.

[22] R. Song, and L. Korba, "How to make e-cash with nonrepudiation and anonvmitv." IEEE. International conference on information technology, 2004, pp. 167-172.

[23] P. Limsaiprom, P. Praneetpolgrang and P. Subsermsri, "Security Visualization Analytics Model in Online Social Networks Using Data Mining and Graph-based Structure Algorithms" International Journal of Information Technology and Computer Science, 2014, vol6.

[24] W. Juang, "A practical anonymous payment scheme for electronic commerce." Computers \& Mathematics with Applications, vol. 46, 2003, pp.1787-1798.

\section{Authors' Profiles}

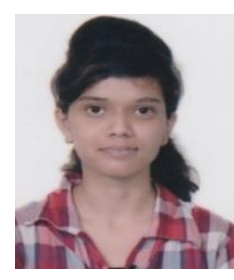

Harshita is an Assistant Professor in department of computer science in ITM University, M.P. She pursued M. Tech in computer science from Mody University of science and technology, Rajasthan. She received her graduation degree from NRIITM, Gwalior which comes under RGPV, Bhopal.

Her areas of interests are cryptography, security and data structures.

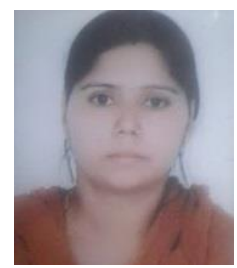

Sarvesh Tanwar is an Assistant Professor in department of computer science in Mody University of science and technology, Rajasthan. She has more than 6 year experience in teaching. She received her M.Tech degree from MMU, Mullana, Haryana.

Her main areas of interests are cryptography and network security and OOPS.

How to cite this paper: Harshita, Sarvesh Tanwar, "Implementation of Fair-exchange and Anonymous Online E- cash Protocol for E-commerce", International Journal of Information Technology and Computer Science (IJITCS), Vol.8, No.8, pp.66-74, 2016. DOI: 10.5815/ijitcs.2016.08.08 